\title{
10
}

\section{Migration Mechanisms of the Middle Range: On the Concept of Reverse Cumulative Causation}

Godfried Engbersen, Erik Snel and Alina Esteves

\section{Introduction}

In a recent collection of articles on the significance of the work by the American sociologist R.K. Merton, Charles Tilly (2010, p. 55) argued for mechanism-based explanations of the middle range. In his own words, 'mechanistic explanations offer a distinctive, superior grasp of how social processes actually work'. Tilly's plea fits in a development in which mechanism-based explanations are increasingly gaining attention. This development is in response to shortcomings in causal explanations and is also expressive of the conviction that proper explanations should detail the 'cogs and wheels' or the 'nuts and bolts' of the causal process through which the outcomes to be explained are brought about (Elster, 1989; Hedström and Ylikoski, 2010; Tilly, 2005; 2010). Another important factor is the explicit interest in developing a theory of action that combines explanations at the macro-level with explanations at the micro-level (Coleman, 1986; 1990).

In this chapter, we argue that mechanism-based explanations are highly relevant for the field of migration studies (see also Faist, 2015). We will illustrate this by means of the migration mechanism of 'cumulative causation' or 'circular migration' as developed by Myrdal and Massey. However, this mechanism was mostly used to explain the continuation and expansion of migration flows. In this chapter we focus on reverse cumulative causation. Reverse cumulative causation relates to feedback mechanisms that contribute to the discontinuation and decline of migration flows. A second aim of this chapter is to show the importance of moving beyond migrant networks to understand how the mechanism of reverse cumulative causation works. Therefore, we 
analyse how macro-level factors influence the functioning of Brazilian and Moroccan migrants and their networks (the macro-micro problem). We shall explain the mechanism of reverse cumulative causation with reference to two examples of declining migration: the migration corridors from Brazil to Portugal and from Morocco to the Netherlands. We will draw on qualitative and quantitative THEMIS data collected for analysing the Brazil-Portugal corridor and the Morocco-Netherlands corridor (see chapters 6 and 7).

This chapter is organised as follows. In the next section, we discuss the importance of mechanism-based explanations and introduce the mechanism of reverse cumulative causation. After that we analyse the workings of the mechanism of reverse cumulative causation. We will focus in particular on the 'agentic' role of individual migrants and their networks in reducing immigration (Paul, 2011, p. 1844; Bakewell et al., 2013). The chapter concludes with a discussion of the main findings.

\section{The idea and structure of mechanism-based explanations}

In their overview article on causal mechanisms in the social sciences, Hedström and Ylikoski (2010, pp. 50-52) posit four generally shared ideas on what characterises a mechanism:

1. A mechanism is identified by the kind of effect or phenomenon it produces.

2. A mechanism is a causal notion.

3. A mechanism has a structure: 'When a mechanism-based explanation opens the black box, it discloses this structure. It turns the black box into a transparent box and makes visible how the participating entities and their properties, activities, and relations produce the effect of interest' (Hedström and Ylikoski, 2010, p. 51).

4. Mechanisms form a hierarchy: 'While a mechanism at one level presupposes or takes for granted the existence of certain entities with characteristic properties and entities, it is expected that there are lower-level mechanisms that explain them' (Hedström and Ylikoski, 2010, p. 52).

In elaborating their mechanism-based explanations in sociology, Hedström and Ylikoski mark out two positions. First they point to the necessity of systematically integrating theoretical and empirical work, connecting to Merton's plea for sociological theories of the middle range. These are theories that can explain diverse social phenomena 
but that do not pretend to be all encompassing, general theories. ${ }^{1}$ As an example they refer to Merton's mechanism of the self-fulfilling prophecy. A typical aspect of how self-fulfilling prophecies work is the feedback mechanism. An incorrect definition of the situation (the unjust assumption that a solvent bank is in financial trouble) brings forth certain behaviour (customers pull their money out) which influences other people's beliefs and triggers the same collective behaviour in them (resulting in a 'run on the bank'). In this way a 'self-reinforcing and belief-centred cycle' is created and an incorrect situation definition ends up becoming true (the bank actually does go bankrupt) (Hedström and Ylikoski, 2010, p. 62). This mechanism of the self-fulfilling prophecy has been used to explain a range of different types of phenomena (including ethnic and race relations).

The second position marked out by Hedström and Ylikoski is that it is the primary task of sociology to explain collective phenomena. For this, and in line with Coleman (Coleman, 1986; 1990), they state that it is unsatisfactory to explain macro-phenomena in terms of other macro-phenomena. Their 'macro-micro-macro' model is based on the assumption that a macro-phenomenon is the (unintended) result of the actions of a large number of individuals in micro-situations. Here they note that 'explanatory understanding is only achieved by recognising that actions take place in relational structures' (Hedström and Ylikoski, 2010, p. 59). Figure 10.1 - also known as the 'Coleman boat' - visualises their approach. A relationship is assumed to exist between certain social facts, social structures or institutions and certain social phenomena. ${ }^{2}$ Hedström and Ylikoski (2010, p. 59) use the term 'macro-level associations'. As noted above, they argue that scientific explanations that are restricted to macro-level relations are unsatisfactory, as they do not specify the causal mechanisms by which macro-properties are related to each other (cf. Coleman, 1990, pp. 6-7). To explain macro-level associations, three analytical steps are required: first, to identify the 'situational mechanism' by which specific macro-factors shape and constrain individuals' desires, beliefs and motivations (macro-to-micro, arrow 1). The second step is to establish a relationship between individuals' desires, beliefs and motivations and their individual actions. This is known as the 'action-formation mechanism' (micro-to-micro, arrow 2). The third step is to analyse how individual actions interact and interfere with one another, leading to intended and unintended macro-outcomes. This is the 'transformational mechanism' (micro-to-macro, arrow 3).

These insights are relevant for the field of migration studies. This can be illustrated by reference to Massey's theory (1990; Massey et al., 1998) 


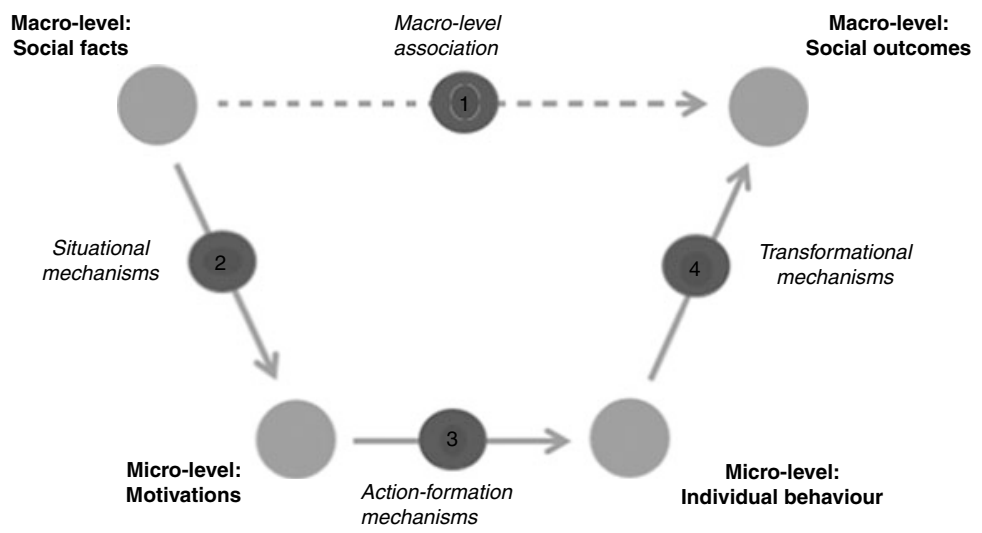

Figure 10.1 A typology of social mechanisms (based on Hedström \& Ylikoski, 2010)

on cumulative causation. This is one of the most developed theories in the migration literature, offering an explanation for self-reinforcing processes of Mexican-US migration and other patterns of international migration. It also illustrates the significance of mechanism-based explanations, because of the systematic focus on the influence of political-economic and local factors on individual behaviour, households, migrant networks, community structures and belief formations (migration cultures and the role of migration aspirations). The mechanism of cumulative causation consists of a hierarchy of interrelated mechanisms. In the study Worlds in Motion, Massey et al. (1998) list eight ways through which migration acquires a self-perpetuating and self-reinforcing character. ${ }^{3}$ A crucial mechanism is the mobilisation of resources from the social networks in which migrants are embedded (accumulation of social capital) (Fussell and Massey, 2004, p. 152). Ties with migrants increase the likelihood of migration, as they reduce the costs and boost the anticipated benefits of migration. The first pioneering migrants need to find their way in the destination country, and for them the costs are high. They can then help out aspiring and new migrants with jobs, housing and relevant documents, making it easier and hence cheaper for them. In the words of Massey (1990, p. 8):

[E]xpanding networks cause the costs of migration to fall and the probability of migration to rise; these trends feed off one another, and over time migration spreads out to encompass all segments of a 
society. This feedback occurs because the networks are created by the act of migration itself.

Massey argues in later work that the accumulation of social capital is the primary mechanism underlying cumulative causation (Fussell and Massey, 2004, p. 152). He strongly emphasises the role of migrant networks as the channel of migration-facilitating feedback.

A second important mechanism is the establishment of a migration culture. As migration becomes increasingly common in a community, the values and cultural perceptions of that community evolve in a way that increases the likelihood of future migration. Migration is increasingly seen as a valuable and habitual ambition (Massey et al., 1998; Heering et al., 2004). However, Massey et al. (1998, p. 48) also acknowledge 'limits' to cumulative causation. They argue that the mechanism of cumulative causation is especially related to rural contexts, and that at a certain point the migration process reaches 'network saturation', so that the process of migration loses its dynamic (Massey, 1990; Fussell and Massey, 2004). Economic developments (labour shortages and rising local wages) in the sending regions may contribute to the reduction of the out-movement of migrants and to network saturation.

Massey's work is compatible with Hedström and Ylikoski's conceptual framework. Massey shows (1) how economic factors, migration policy and local relationships influence the desires and aspirations of potential migrants to emigrate (situational mechanism); (2) that these aspirations lead to actual migration behaviour and to mobilising information, money, housing and jobs, as the resources required for a successful migration (action-formation mechanism); and (3) that the aggregated result of these individual actions is the emergence, in both the sending and receiving country, of a migration-facilitating infrastructure, so that migration becomes self-sustaining (transformational mechanism).

\section{The mechanism of reverse cumulative causation}

The mechanism of cumulative causation provides a valuable framework to explain various migrant movements within specific migration corridors analysed by the THEMIS project. One example is the migration from Morocco to the Netherlands, due to the recruitment of so-called guest workers since the mid-1960s and the subsequent arrival of partners and children since the mid-1970s (Lucassen and Lucassen, 2011; De Haas, 2005; 2007). The number of first-generation (foreign-born) Moroccans in the Netherlands increased from less than 25,000 in 1974 - 
the formal recruitment stop for guest workers following the so-called oil crisis in those days - to about 168,000 in 2005 , mainly due to processes of family reunification and family formation (migration resulting from the fact that many second-generation Moroccans still found their spouses in Morocco). Another example is the migration from Brazil to Portugal. Although Brazil was always an immigrant receiving country, migration from Brazil to Portugal started in the late 1970s. From the 1970s to 2010, the number of Brazilians in Portugal increased from only 3,000 to almost 120,000 (Fonseca and McGarrigle, 2014). Immigration from Brazil to Portugal started as a middle-class phenomenon: young Brazilians came to Portugal to study due to historical colonial ties and linguistic and cultural links. Since the mid-1990s, it expanded rapidly and started to include low-skilled migrants. Padilla (2006) refers to this shift as the 'proletarisation' of migration from Brazil to Portugal. Other scholars speak of a 'second wave' of low-skilled migrants (see also Bógus, 2007; Peixoto and Figueiredo, 2007). In sum, in Portugal as well as in the Netherlands, economic opportunities, permissive migration policies, support provided by migrant networks and the existence of migration cultures in high migration-impacted regions (such as Mantena in Brazil and Rabat and Nador in Morocco) generated a self-reinforcing process of increasing migration from Brazil to Portugal and from Morocco to the Netherlands.

However, migrant flows from Morocco to the Netherlands began to decline in the second half of the 1990s, while migration flows from Brazil to Portugal started to decline since the recent economic crisis of 2008 (Fonseca et al., this volume, Chapter 6; Snel et al., this volume, Chapter 7). These contemporary patterns of declining migration are to our understanding not the result of 'network saturation', but they are a consequence of a mechanism we categorise as 'reverse cumulative causation'. This mechanism is already visible in Myrdal's (1957) original formulations of cumulative or circular causation, which were reintroduced and developed by Massey in his work on international migration. Myrdal showed in his analysis of world poverty that the dynamics of cumulative causation may cause upward spirals of increasing wealth but also downward spirals of increasing poverty. Often, these two processes are interrelated: the upward spiral of an economy may be an important cause of another's downward spiral (see also Myrdal, 1970; Rigney, 2010).

The theory of cumulative causation describes several mechanisms that lead to upward spirals of migration, while the concept of reverse cumulative causation seeks to specify mechanisms leading to downward spirals of migration. However, in both causes feedback loops are 


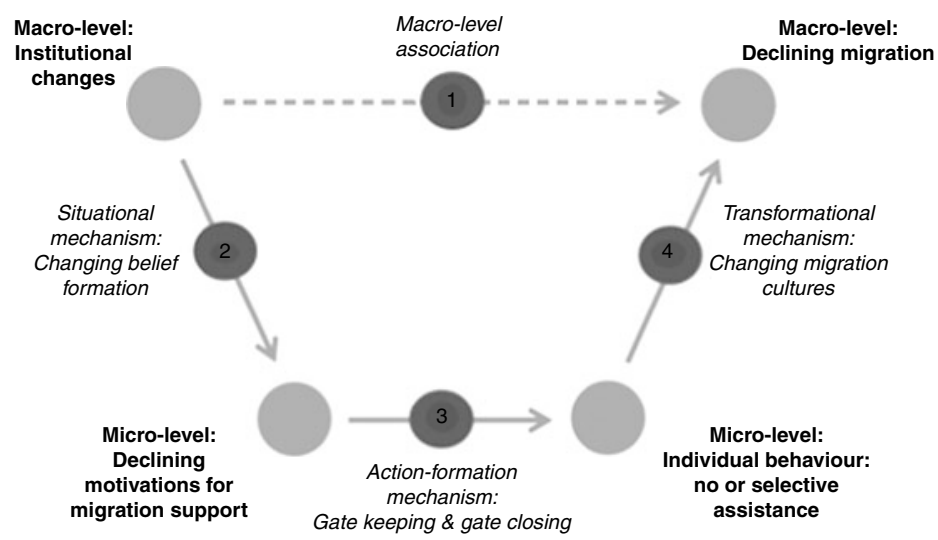

Figure 10.2 Declining immigration from Brazil to Portugal and from Morocco to the Netherlands as a result of reverse cumulative causation

at work that contribute to self-amplifying processes of increasing or decreasing migration. The conceptual model of Hedström and Ylikoski is helpful for specifying the three social mechanisms that generate the process of reverse cumulative causation (see Figure 10.2). Firstly, we assume that three institutional macro-level phenomena (restrictive migration regimes, limited job opportunities and anti-immigration sentiments) negatively influence the beliefs and motivations of settled migrants to support and stimulate potential migrants to move to Portugal and the Netherlands (situational mechanism). Secondly, this negative 'belief formation' (Hedström and Swedberg, 1998, p. 23) of settled migrants regarding migration from Brazil to Portugal and from Morocco to the Netherlands results in deliberate actions not to assist potential migrants, or to provide assistance only very selectively (actionformation mechanism). Thirdly, this migration-undermining feedback towards prospective migrants in the origin countries leads to changes in the migration cultures in Brazil and Morocco in which potential migrants are embedded (transformational mechanism) (De Haas, 2010). As a result, a much more selectively composed group is capable of moving to Portugal and the Netherlands, namely the higher skilled, those who can meet the strict demands of migration policies and those who are less affected by the anti-immigration attitudes. As a result of these three mechanisms, a causal process arises that results in a decline in new migration from Brazil to Portugal and from Morocco to the Netherlands.

The model presented in this chapter has its limitations. The mechanisms on which our model focuses operate at the level of migrants 
and their networks. The effects of macro-economic and political factors in the origin and destination countries are analysed through the consequences they have on migrants' beliefs, assessments and actions. We did not analyse broadcast feedback that operates through impersonal channels, for example information, images and ideas that are transmitted by communication and mass media (see Bakewell and Jolivet, in this volume). Besides, we did not study systemically how Brazilian and Moroccan migration has transformed communities of origin, for example through investments with remittances. In spite of these limitations, our model offers a framework for understanding migrationundermining feedback processes that contribute to declining migration flows.

\section{Declining immigration flows and reverse cumulative causation of migration}

The Brazil-Portugal corridor and the Morocco-Netherlands corridor have different characteristics. The destination surveys show that almost $90 \%$ of the Moroccan respondents lived for more than 10 years in the Netherlands, while about 50\% of the Brazilians in Portugal have lived there for less than five years. Among the Brazilian respondents we found more young, skilled (especially students) and working people. Furthermore, the Brazil-Portugal corridor is characterised by substantial return migration. The Moroccan respondents were older, less skilled and half of them were working. Within the Morocco-Netherlands corridor, there is limited return migration. The surveys in the origin countries show the strong transnational connections of Moroccans to Western Europe due to a long migration tradition, in contrast with Brazil that has a younger immigration tradition.

The overview in Table 10.1 summarises some characteristics of the two migration corridors and the transformations that took place in the 'contexts of reception' in Portugal and the Netherlands in the last decades (Carling and Jolivet, this volume Chapter 2; Fonseca et al., this volume, Chapter 6; Snel et al., this volume, Chapter 7). Although we are dealing with different migration corridors, the changes in the contexts of reception point in the same direction: less receptive migration regimes, fewer job opportunities and a more hostile climate towards immigrants (cf. Portes and Rumbaut, 1990; Portes, 1995).

Fonseca et al. (this volume, Chapter 6) and Snel et al. (this volume, Chapter 7) show that these macro-level changes in the contexts of reception have impact on the assessment of migrants living in Portugal 
Table 10.1 Overview of the characteristics of the Brazil-Portugal and MoroccoNetherlands corridor and the transformation of the contexts of reception in Portugal and the Netherlands

\begin{tabular}{|c|c|c|}
\hline & Corridor Brazil-Portugal & $\begin{array}{l}\text { Corridor } \\
\text { Morocco-Netherlands }\end{array}$ \\
\hline \multirow{4}{*}{$\begin{array}{l}\text { Migration } \\
\text { corridor } \\
\text { characteristics }\end{array}$} & $\begin{array}{l}\text { Young immigration tradition } \\
\text { (from the 1980s) }\end{array}$ & $\begin{array}{l}\text { Old immigration tradition } \\
\text { (from the 1960s) }\end{array}$ \\
\hline & $\begin{array}{l}\text { First mainly professional } \\
\text { middle class and student } \\
\text { migration, later mainly } \\
\text { low-skilled labour migration } \\
\text { and more recently (after 2011) } \\
\text { higher education students }\end{array}$ & $\begin{array}{l}\text { First low-skilled labour } \\
\text { migration, later mainly } \\
\text { low-skilled family reunification } \\
\text { \& family formation }\end{array}$ \\
\hline & Substantial return migration & Limited return migration \\
\hline & $\begin{array}{l}\text { Semi-strong to weak } \\
\text { transnational networks }\end{array}$ & Strong transnational networks \\
\hline \multirow[t]{3}{*}{$\begin{array}{l}\text { Changes in } \\
\text { macro-level } \\
\text { contexts of } \\
\text { reception in } \\
\text { destination } \\
\text { countries }\end{array}$} & $\begin{array}{l}\text { Migration policy: } \\
\text { From a non-issue (1980s) to } \\
\text { permissive \& receptive (1990s } \\
\text { and early 2000s) to more } \\
\text { restrictive (from } 2003 / 2007 \text { ) }\end{array}$ & $\begin{array}{l}\text { Migration policy: } \\
\text { From receptive (1960s) and } \\
\text { permissive (1980s and 1990s) } \\
\text { to very restrictive (from 2000s) }\end{array}$ \\
\hline & $\begin{array}{l}\text { Job opportunities: } \\
\text { From (high) skilled job } \\
\text { opportunities (1980s) to } \\
\text { (partly irregular) low-skilled } \\
\text { job opportunities (1990s and } \\
\text { 2000s) to very limited job } \\
\text { opportunities (from } 2008 \\
\text { onwards) }\end{array}$ & $\begin{array}{l}\text { Job opportunities: } \\
\text { From regular low-skilled job } \\
\text { opportunities (1970s) to } \\
\text { irregular job opportunities } \\
\text { (1980s and 1990s) to very } \\
\text { limited job opportunities } \\
\text { (2000s) }\end{array}$ \\
\hline & $\begin{array}{l}\text { Societal reception: } \\
\text { From tolerance }(1970 \text { s and } \\
1980 \text { s) to welcoming (1990s) } \\
\text { to selective discrimination } \\
(2000 \text { s) }\end{array}$ & $\begin{array}{l}\text { Societal reception: } \\
\text { From welcome (1970s) to } \\
\text { tolerance (1980s and 1990s) to } \\
\text { discontent and hostility (from } \\
2000 \text { s) }\end{array}$ \\
\hline
\end{tabular}

and the Netherlands to support prospective migrants in Brazil and Morocco to move to Western Europe. Snel et al. (Chapter 7) introduce the concept of 'gate closing' which relates to migrants refusing to support co-ethnics to move to the Netherlands, and Fonseca et al. (Chapter 6) speak of 'proactively discouraging people from emigrating to Portugal'. 
In the next section, we examine the impact of the institutional changes on settled migrants in Portugal and the Netherlands with the help of the model of Hedström and Ylikoski. First, we analyse the changing beliefs and motivations of settled migrants to support prospective migrants. Second, we show that settled migrants predominantly act as 'gate keepers' and 'gate closers' towards prospective migrants (Böcker, 1994; Paul, 2013). Third, we argue that these migration-undermining acts affect migration cultures in Brazil and Morocco.

\section{Situational mechanism: Declining motivation for supporting potential migrants}

The qualitative interviews held in both the origin and destination countries indicate that all three macro-factors are at work and influence the motivations to support prospective migrants to move to Europe (Fonseca et al., this volume, Chapter 6; Snel et al., this volume, Chapter 7; Engbersen et al., 2013). However, the outcomes of regression analyses show that in the Dutch case the respondents' unwillingness to support potential newcomers is mainly related to the stricter migration policies and the harsh Dutch public climate about immigration and Muslims (Snel et al., this volume, Chapter 7), whereas in the Portuguese case, economic opportunities are an important factor behind the critical stance towards potential migrants in Brazil (Fonseca et al., this volume, Chapter 6). Table 10.2 indicates that the majority of settled migrants in Portugal and the Netherlands is not recommending prospective migrants to move to Europe. There is a strong disbelief in the relevance of a migration project. Furthermore, a minority of the respondents add they would only give support in some cases and not in other cases. This shows the growing selectiveness in the support provided to newcomers.

Table 10.2 Respondents' inclination to recommend people from Brazil to move to Portugal $(\mathrm{N}=400)$ and from Morocco to the Netherlands $(\mathrm{N}=420)(\%)$

\begin{tabular}{lcc}
\hline & $\begin{array}{l}\text { Corridor } \\
\text { Portugal-Brazil }\end{array}$ & $\begin{array}{l}\text { Corridor } \\
\text { Netherlands-Morocco }\end{array}$ \\
\hline Yes & 20.8 & 8.5 \\
No & 68.2 & 79.3 \\
In some cases, but $\quad 11.0$ & 12.2 \\
$\quad$ not in others & & \\
\hline
\end{tabular}

Source: THEMIS Destination country survey of Brazilians in Portugal and Moroccans in the Netherlands (unweighted data). 
In the literature one can find abundant evidence of how settled migrants do not accurately portray life in the receiving society (Mahler, 1995). Even though they have often obtained positions in the lower strata of the receiving society, they send positive images to the origin country of wealth they have gained, sometimes even increasing their debts in order to do so. While we have indications that this was certainly true for Moroccan immigrants in the Netherlands in the past, this has changed today (Lucassen and Lucassen, 2011). Many respondents explicitly mention that economic opportunities are not as attractive as they used to be. Settled Brazilian migrants in Portugal point to the limited economic opportunities for Brazilian newcomers in Portugal. Isabella tells us:

I never seen on the Internet, for instance on social media sites, any Brazilian saying Portugal is wonderful, having many job opportunities (...) actually quite the opposite, most of people do say it is difficult to find work in Portugal, even before the crisis. It is been always like that since I started working with migration.

(Isabella, female, 51, Brazil-Portugal, migrant)

Moroccan migrants in the Netherlands express the same negative view on the current job opportunities. Ilham says: 'There is no work here. If they come to Holland they will only get into trouble. In the past there was enough work, but not anymore' (Ilham, female, 82, MoroccoNetherlands, migrant). Other settled migrants also mention that changing economic circumstances in the Netherlands are making life more difficult and less attractive for Moroccan immigrants. Souhaila, who spent nearly 40 years in the Netherlands, mentions: 'There is no money to make here. There are no jobs anymore. It's better to stay over there' (Souhaila, female, 64, Morocco-Netherlands).

Apart from the limited job opportunities, many settled migrants mention that it has become very difficult for Brazilians and Moroccans to migrate to Portugal and the Netherlands due to the selective and restrictive migration policies. Fatima, a 33-year-old Moroccan, elaborates: 'Today it is difficult to obtain a visa. Also for the request you must have a job and a large income. The immigration policies are also stricter than before. Migrants have to do a lot of tests and have to learn a lot about Dutch culture' (Fatima, female, 33, MoroccoNetherlands). In the case of Brazilians in Portugal, they do not have to pass a language and civic integration test in order to marry a partner in Portugal. Moreover, if they have a Portuguese grandparent, they can 
easily obtain Portuguese citizenship. Nevertheless, anti-irregular migration policies have become more restrictive and there are no amnesty programmes nowadays that make regularisation possible. These stricter policies reduce the job opportunities and life chances of irregular Brazilian migrants substantially (Engbersen and Broeders, 2009):

And if I brought someone, employment is difficult, to obtain a visa is difficult, nobody gives employment like that. I hire people in the nursing home where I work, they have to be documented, why? Because if the inspection knocks on the door, I'm the first to go to jail because I admitted someone who is illegal (...).

(Gisele, female, 45, Brazil-Portugal, migrant)

For those living here [in Portugal], those already with documents, it is difficult; for someone coming without documents it is even worse!

(Oscar, male, 39, Brazil-Portugal, migrant)

Brazilian and Moroccan migrants furthermore feel that the societal reception in Portugal and the Netherlands has changed and that immigrants are now treated with prejudice. Many Moroccan respondents elaborated on their actual negative experiences with native Dutch people and how bad such experiences make them feel. El Ghazi tells us: 'Eighty percent are racists. One day I entered a café in Rotterdam to support the Dutch soccer team and they didn't want me to enter. Things like that upset me' (male, 27, Morocco-Netherlands, migrant). Hassan, a 41-year-old skilled worker, says: 'Sometimes you get the feeling that people hate you. They hate you for who you are and they hate your presence' (male, Morocco-Netherlands, migrant). Like El Ghazi and Hassan, respondents indicate that the attitudes of Dutch people towards them have changed over the years, especially with respect to their Islamic religion (see Snel et al., this volume, Chapter 7).

In Portugal, other mechanisms of discrimination are at work. Many Brazilians - especially women - often feel discriminated against (see Fonseca et al. in this volume). According to Malheiros (2007), discriminatory attitudes towards Brazilian immigrants are becoming more frequent. Brazilian women became the main victims of stereotypes that tend to 'exoticise' their image, often seeing them as 'exotic and easy'. The discrimination is also felt in the labour market. The high unemployment rates among nationals and immigrants increase the competition for jobs and elevate social tensions between these groups. However, the changes in the societal reception of Brazilians are related not only to the 
economic crisis but also to the rapid and significant growth of the size of the Brazilian community in Portugal, the features of the so-called second wave that arrived in Portugal in the late 1990s (poor and low skilled), their incorporation in the secondary segment of the labour market and to specific episodes of violent crime which involved Brazilian nationals (Malheiros, 2007).

The growing competition in the labour market and the discriminatory attitudes of Portuguese employers can be found in Bernardo's words who migrated to Portugal in 1990. He reveals how important Brazilian professionals (e.g., dentists, media and communication experts) were to train and teach Portuguese professionals and how things changed over time:

They were well considered. Nowadays they want to see the back of us (...) I never felt prejudice. If there was prejudice, I didn't understand. Nowadays, I already feel a bit (...) in my area I feel [prejudice] because "he is taking my place here".

(male, 57, migrant)

The negative assessments of Brazilian and Moroccan migrants in Portugal and the Netherlands on migration polices, job opportunities and societal reception contribute to a growing disbelief in the relevance and possibility of migration. This disbelief leads to acts of gate keeping and gate closing among settled migrants in Brazil and Portugal. These outcomes relate to the action-formation mechanism.

\section{The action-formation mechanism: Gate keeping and gate closing}

The results of the destination surveys show that more than $54 \%$ of the Brazilian respondents do not encourage anyone to come to Portugal, and that nearly $42 \%$ have actually discouraged someone from migrating. The Dutch data are more significant. They show that almost $86 \%$ of the Moroccan respondents do not encourage migration and that more than $39 \%$ is actively discouraging further migration (see Table 10.3).

The qualitative interviews give insight into the process of discouragement. First, settled migrants give prospective migrants realistic information regarding the worsening economic climate in Portugal and the Netherlands and the scarcity of decent jobs compared to the past. Second, migrants try to explain to prospective migrants in Brazil and Morocco that it is complicated to get into Portugal and the Netherlands, 
Table 10.3 Encouragement and discouragement of migration from settled Brazilian migrants in Portugal and settled Moroccan migrants in the Netherlands (\%)

\begin{tabular}{lcc}
\hline & Yes & No \\
\hline Brazilians in Portugal & & \\
Encouraging migration $(\mathrm{N}=400)$ & 45.8 & 54.3 \\
Discouraging migration $(\mathrm{N}=400)$ & 41.8 & 58.3 \\
Moroccans in Rotterdam & & \\
Encouraging migration $(\mathrm{N}=418)$ & 14.1 & 85.9 \\
Discouraging migration $(\mathrm{N}=416)$ & 39.2 & 60.8 \\
\hline
\end{tabular}

Source: THEMIS destination country survey of Brazilians in Portugal and Moroccans in the Netherlands (unweighted data).

due to the increasing restrictions on immigration. Besides providing information on the unfavourable economic climate and migration policies, they also tell potential migrants about the negative social climate towards immigrants. This final aspect is very relevant for the Netherlands in which anti-immigration and anti-Muslim sentiments became very clear.

They [family and friends in Morocco] always ask for help to come to the Netherlands. I always say the same: that it is difficult to find work and that there is high unemployment (...). If they say that they want to come to the Netherlands and ask if I can help them, then I always say that times have changed and that getting work as an illegal resident is extremely difficult (...) I tell people not to come to the Netherlands because in reality it is tough. I try not to sketch a nice picture of the Netherlands.

(Insaf, female, 45, Morocco-Netherlands)

The situation has changed dramatically. How are you going to find decent work without the right papers? Marriage also comes with a lot of hurdles. Your spouse has to have a fairly high and stable income, you need to take exams in your home country and when you get here there's another exam you need to take within a year (....) I would advise them not to migrate to Europe. I would tell them to stay where they are.

(Hassan, male, 41, Morocco-Netherlands)

I really like this country in many respects, but there is one thing that I think is very dangerous: the fact that politicians like Geert Wilders 
are becoming very popular. For Muslims this means that their rights to practice their religion are in danger. I think a lot of European countries - including the Netherlands - are very afraid of Islam, and they are trying to keep this religion outside their borders (....) Muslims are not welcome anymore. That is why I would be cautious with giving Moroccans the advice to come here.

(Tarik, male, 33, Morocco-Netherlands)

Among the Brazilian migrants interviewed in Portugal, the feeling is quite similar. Especially, the lack of jobs plays a major role among settled Brazilian migrants in Portugal to justify the negative advice given to potential Brazilian migrants:

Considering the current crisis the country, I would not advise [Brazilians to come to Portugal]. Due to the unemployment here, to give opportunity to the people already here. In my opinion, they should stay in their country (...) because there's so much unemployment here $(. .$.$) if a job comes up, those living here have more$ opportunities. If they come, then things get even more complicated, I think.

(Joana, female, 42, Brazil-Portugal)

I tell them 'no use thinking about came here!' I even had a niece who was thinking of going to Spain now, because her mother's boyfriend lives in Spain. But I told her: 'Don't come, it's not worth coming!' That's what I tell them!

(Joaquim, male, 37, Brazil-Portugal)

These qualitative findings are supported by the results of the destination surveys among Brazilians in Portugal and Moroccans in the Netherlands. The Brazilian and Moroccan respondents were asked about their intentions to support prospective migrants in five areas, namely (1) obtaining migration documents, such as a visa or residence permit, (2) covering travel costs, (3) finding a job, (4) finding housing and (5) accommodating someone at home. They were also asked whether they received support from others during their migration to Portugal and the Netherlands in four areas: (1) financing travel costs, (2) obtaining migration papers, (3) finding a first job and (4) their initial housing in the Netherlands. The results indicate that, today, nearly $52 \%$ of the Brazilian and almost 70\% of the Moroccan respondents have no intentions of offering support, although $77 \%$ of the Brazilian and $85 \%$ of 
Table 10.4 The intention to give assistance today and received assistance during one's own migration (\%)

\begin{tabular}{|c|c|c|c|c|}
\hline & \multicolumn{2}{|c|}{$\begin{array}{l}\text { Settled Brazilians in } \\
\text { Portugal }(\mathrm{N}=400)\end{array}$} & \multicolumn{2}{|c|}{$\begin{array}{l}\text { Settled Moroccans in the } \\
\text { Netherlands }(N=420)\end{array}$} \\
\hline & Intention & Received & Intention & Received \\
\hline None & 57.7 & 5.0 & 69.0 & 3.6 \\
\hline 1 domain & 8.5 & 22.0 & 10.7 & 11.0 \\
\hline 2 domains & 13.0 & 36.3 & 11.0 & 46.0 \\
\hline 3 domains & 13.0 & 31.5 & 3.6 & 34.8 \\
\hline 4 domains & 11.0 & 5.3 & 3.3 & 4.8 \\
\hline 5 domains & 2.8 & - & 2.4 & - \\
\hline
\end{tabular}

Source: THEMIS destination country survey of Brazilians in Portugal and Moroccans in the Netherlands (unweighted data).

the Moroccan respondents received support in two or more areas during their migration to Europe (see Table 10.4).

However, the quantitative and qualitative analyses also reveal that a certain group continues to function as selective 'gate keepers', yet only under specific conditions (Carling and Jolivet, in this volume). Three important conditions are possession of regular residence documents, being highly skilled in order to have job opportunities and study purposes. For individuals that meet these criteria migration may still be worthwhile. This is especially true for contemporary students, who are an important constituent of the Brazil-Portugal corridor (Carling and Jolivet, this volume, Chapter 2; Fonseca et al., this volume, Chapter 7).

\section{The transformational mechanism: Migration cultures in transition}

The third mechanism involves the aggregation of migrationundermining feedback by individuals, which leads to changes in migration aspirations and cultures. Our qualitative analysis reveals that there are indications that this transformation is indeed taking place in Brazil and Morocco. First, we notice a general decline in the aspirations to leave Brazil and Morocco. This decline is related to improved economic conditions in the sending regions (especially in Brazil) but is also the result of the failed migration project of Brazilian and Moroccan migrants and the migration-undermining feedback they receive from return migrants and family members who live in Portugal and the Netherlands. A common observation among especially the Brazilian respondents is that they don't see people leaving the country anymore, 
but rather earlier migrants returning to Brazil: 'Now, my brother is coming back, he also gave up. He is returning due to the economic crisis which affected Portugal a lot' (Milton, male, 35, Brazil-Portugal, family member). 'The number of people who return is increasing. People are coming back, they are not going so much now, because it is not worth anymore, to go to Portugal now' (Ema, female, 42, BrazilPortugal, return migrant). 'Now, I see people returning because there is no more work (in Europe). It is very difficult, things are expensive, food is expensive, everything is expensive, (...) it's difficult. Thus, I think that the only trend is not to emigrate anymore' (Amanda, female, 25, Brazil-Portugal, return migrant).

The majority of the respondents we interviewed in Brazil and Morocco consider it unwise to migrate to Portugal or the Netherlands today (or to Europe in general). Their negative perceptions are influenced by the migration-undermining feedback received from settled migrants. This feedback influences migration aspirations in Brazil and Morocco. There is less interest in migration to Portugal and the Netherlands and to other parts of Europe:

The only means through which I know about Holland is from what my cousins tell me. My cousins also told me how they were victims of ethnic profiling. If people there know that you are a Muslim or an Arab they automatically label you as dangerous at best, and as a terrorist at worst. My cousins were victims of this stereotyping. So are veiled women, who are also viewed with suspicion.

(Lahcen, male, 27, Morocco-Netherlands, family member)

I know that the economic situation in the Netherlands is not that good. Even my cousin who has been in the Netherlands for quite some time said that it is more and more difficult to find a job. He has not even saved up any money to invest in projects here in Morocco. If my cousin who has been in the Netherlands for a long time did not make it, how could a newcomer like me ever achieve something there?

(Miro, male, 26, Morcco-Netherlands, family member)

She does not advise people to go anymore because it's not the same as it was in the beginning. When she went, it was easier to get a job.

(Heloísa, female, 59, Brazil-Portugal, family member)

I am always talking with my friends who live there [in Portugal] (...) and I hear them saying that things tighten a lot.

(Marina, female, 39, Brazil-Portugal, return migrant) 
Our respondents in Brazil and Morocco also mention the increasing opportunities and prosperity in Brazil and Morocco, in contrast to the declining economic and legal opportunities in Europe:

Migrants used to come with large of sums of money and help others, for example to buy houses, land, and so forth. Now people from Nador see for themselves that migrants have become very mean and unwilling to spend more money in Morocco. Now when migrants come to my restaurant, they congratulate me for having decided to go back to Morocco for good.

(Aziz, male, 55, Morocco-Netherlands, return migrant)

Nowadays, with regard not only to Portugal but to almost all European countries, some of them are saved [from this crisis] but people are retuning more, isn't it? Because people who are here [in Brazil] have nothing to earn in Portugal, Spain, because of this financial crisis (...) it affected some countries in particular. Portugal was one of them, Spain also, Italy is now one of them, France is now one of them, do you understand? With this [crisis] people who are there begin to live with difficulties.

(Milton, female, 35, Brazil-Portugal, family member)

The migration-undermining feedback by settled migrants and return migrants together with changes in the economic conditions in Portugal and Morocco contributes to changes in migration cultures. The migration discourse in Morocco has become less widespread, according to the 19-year-old housewife Soumi who lives in Tawrirt and whose father and uncle left for the Netherlands in the early 1980s.

At the beginning of 2001, everyone talked about migration. Every day I heard about someone from my family or neighbours who had migrated. But people are no longer interested in migration, only a few youths dream of going abroad, especially to Spain or France. They dream of making a lot of money, owning beautiful cars, houses and getting married. The obstacle that stops them is that it is so complicated to get the official documents in order to leave Morocco. The others do not think about migration any more, since they hear about a lot of people who went abroad and came back to Morocco after 
a failed experience. There are no more jobs available, so then they found themselves without the money they borrowed to migrate, and without work in Europe. Most emigrants travelled 10 years ago. These were the golden years of emigration.

(family member)

The changed migration aspirations and preferences are also observed in the accounts of the Brazilian and Moroccan migrants. When they go on a holiday to Brazil or Morocco or when they speak to friends or relatives on the phone, they are not asked about their migration experiences or possible assistance as much as in the past. Hassan, a 41-year-old Moroccan, responds:

Of course, I know a lot of people, and it always comes up one way or the other. How's life in Holland, how's life in exile, as they call it? But almost every one of them assures me that they have no interest in migrating to Europe. There is nothing left to do in Europe, they say. The mentality has changed. People find something to do and put their thoughts of migration to rest. Years ago everybody was talking about leaving the country. (...) The young people nowadays ask about Europe out of general interest, but not to actually live there. (...) You used to hear talk of migration all the time, all the time young people scheming in the street, telling each other their plans or giving each other tips on the easiest way to leave the country. Now when you meet someone you have a casual conversation and a coffee together and then they are on their way again, going about their business.

(male, Morocco-Netherlands, migrant)

According to Davi, living in Portugal since 1990, who goes on holidays to Brazil almost every year:

There are many Brazilians leaving Portugal to return to Brazil, because nowadays Brazil is a much more developed country (...) Brazil is a country with lots of potential, thus I think that tradition [of emigrating] is a bit weaker. It's not worth leaving when you are in a country with lots of potential and Brazil is one of the countries growing faster and I believe the reverse is happening in Portugal. Thus so many 
migrants, not only Brazilians, are returning to their home countries or choosing other countries for living.

(male, 47)

The more critical stance towards migration to Europe does not imply that migration is no longer an option. The surveys in the origin countries show that a substantial number of respondents still have the aspiration to migrate (see Table 10.5). More than 50\% of the Moroccan population has migration aspirations. The migration aspirations in Brazil are substantially lower, especially in the urban area of Campinas where economic conditions have improved substantially in the last decade (Carling, in this volume).

However, for those who aspire to migrate, the preferred destinations are changing. For Brazilians who aspire to migrate, the United States is on top of the list because of the economic opportunities (see Table 10.6). European countries, including Portugal, have become less popular among the Brazilian population. By contrast, European countries are still preferred destination countries for the Moroccan population due to extensive transnational connections (especially in relation to family and student migration). Germany is mentioned relatively frequently, even though the Moroccan diaspora there is much smaller than in France, Spain, Italy, the Netherlands or Belgium. However, Germany is attractive because of the economic opportunities that it offers.

We also note an interest among Moroccan respondents in moving to countries like the United States and Canada (see Table 10.5). For highly skilled Moroccans (including students), the United States and Canada are becoming more popular because of the economic opportunities and also the presumed tolerant social climate there:

Table 10.5 Proportion of Moroccans and Brazilian respondents who would migrate to another country if they had the opportunity (\%)

\begin{tabular}{lcc}
\hline & Moroccans $(\mathrm{N}=401)$ & Brazilians $(\mathrm{N}=\mathbf{4 2 5})$ \\
\hline Yes, go abroad & 52.1 & 32.2 \\
No, stay in Morocco/Brazil & 46.9 & 67.5 \\
Don't know/missing & 0.9 & 0.2 \\
Total & 100.0 & 100.0 \\
\hline
\end{tabular}

Source: THEMIS origin country survey: Brazil and Morocco. 
Well, not so many people want to travel to Holland and as I told you nowadays the most favourite destination for most Moroccans is Canada because it is an open and tolerant country, unlike Europe where the economic situation and the xenophobia are making life very hard for migrants.

(Jamal, male, 49, Morocco-Netherlands, migrant)

Yes, people, especially students, are still interested in going to countries like Canada, the United States or France. (...) I think that more and more students are migrating abroad. Immigration relating to education is on the rise. This brain drain is becoming more important than migration for economic reasons.

(Zahra, female, 52, Morocco-Netherlands, family member)

In sum, migration cultures in the areas of Campinas and Mantena in Brazil and the Rabat and Nador areas in Morocco are in a process of change. There seems to be less interest in migration to Portugal and the Netherlands. This is partly due to the critical feedback from

Table 10.6 Preferred country of destination (first preference) of Brazilians and Moroccans who would migrate to another country if they had the opportunity (\%)

\begin{tabular}{lr} 
Brazilians $(\mathbf{N}=\mathbf{1 3 8})$ & \\
United States of America & 40.6 \\
Italy & 13.8 \\
Portugal & 10.1 \\
Germany & 6.5 \\
Other EU countries & 18.8 \\
Other non-EU countries & 9.4 \\
Don't know & 0.7 \\
Moroccans $(\mathrm{N}=213)$ & \\
France & 19.7 \\
Germany & 19.7 \\
Belgium & 13.1 \\
Netherlands & 12.2 \\
Spain & 7.0 \\
Other EU countries & 8.9 \\
Canada and USA & 9.0 \\
Other non-EU countries & 6.1 \\
Don't know/missing & 4.2 \\
\hline
\end{tabular}

Source: THEMIS origin country survey: Brazil and Morocco. 
family members who have settled in Portugal and the Netherlands or from migrants who have returned. Furthermore, people are also less interested in migration because the opportunities in Brazil (especially in Campinas) and in Morocco (especially in the Rabat region) have improved.

\section{Conclusion and discussion}

This chapter has argued that mechanism-based explanations are relevant for the field of migration studies. This has been elaborated further with reference to the mechanism of reverse cumulative causation. First, we postulated that institutional changes at the macro-level (migration policies, labour market opportunities and societal reception) have consequences for the motivations of individual migrants to offer support. The more restrictive Portuguese and Dutch migration policies, the declining job opportunities and the hostile societal reception of immigrants have reduced the motivation of settled migrants to assist potential migrants. These changes have also induced strategies of gate keeping and gate closing (migration-undermining feedback).

We further demonstrated that the critical feedback provided by settled and return migrants to potential migrants induces changes in migration aspirations and migration cultures. The three institutional changes have, of course, a direct effect on the decline in migration from Brazil to Portugal and from Morocco to the Netherlands. However, it is the combination of direct effects and the indirect effects that run via migrant networks that partly explain the decrease in migration. Other relevant factors are the migration-undermining information prospective migrants receive through impersonal channels (broadcast feedback) or changing economic opportunities in the origin countries.

Our findings furthermore indicate that for a smaller group of people, migration from Brazil to Portugal and from Morocco to the Netherlands may still be worthwhile. These are higher skilled migrants and migrants who migrate in a legal manner such as through marriage, for education purposes or through special programmes for the highly skilled. We may hypothesise that some of these categories - especially the higher skilled have a more individualistic lifestyle and are often staying temporarily in the destination country. For these reasons they are less inclined and less able to give prospective migrants genuine assistance for moving to Europe. This will further reinforce the mechanism of reverse cumulative causation. 
Reverse cumulative causation is a 'mechanism of the middle range' (Tilly, 2010) that can be used to explain specific patterns within specific migration corridors. It remains important, however, to examine the contextual factors involved in each migration corridor. Thus, there is an increasing amount of migration from Brazil and Ukraine to the Netherlands, while both migrant groups would seem to be affected by the same macro-conditions in the Netherlands as Moroccans. One explanation for this growth could be that both groups occupy specific niches in the urban and rural labour markets. For Brazilians, this is mostly domestic work in the Amsterdam labour market, while Ukrainians mostly work in horticulture in the areas around the cities of Rotterdam and The Hague. The Brazilian migrants exhibit the social mechanism, described by Tilly (2005), of 'opportunity hoarding': jobs in the domestic work sector are divided among Brazilian migrants (the 'in-group'), while shutting out other migrant groups (the 'out-group') (see also Faist et al., 2015). As a result, they are able to guarantee specific jobs for newcomers from Brazil.

It is furthermore easy for these two groups to evade the restrictive migration policy: Brazilian citizens are generally allowed to enter the Netherlands (or any other Schengen area) without having applied for a visa (Roggeveen and Van Meeteren, 2013), while Ukrainians can travel to the Netherlands fairly easily via Poland (that became member of the European Union in 2004). Brazilians are moreover treated positively by the native Dutch population. In other words, macro-level factors in the Netherlands work out differently for different migrant groups. These provisional explanations require a closer study of the Brazil-Netherlands and Ukraine-Netherlands corridors, for which we can use the macromicro-macro model presented in this chapter. The mechanism of reverse cumulative causation can also be used to explain other declining migration flows, for instance the declining migration from Turkey to Western Europe.

\section{Notes}

1. Tilly writes (2010, p. 56):

Mechanism-process accounts reject covering-law regularities for large structures such as international systems and for vast sequences such as democratization. Instead they lend themselves to 'local theory' in which the explanatory mechanisms and processes operate quite broadly, but combine locally as a function of initial conditions and adjacent processes to produce distinctive trajectories and outcomes. 
2. Coleman's well-known example based on Max Weber is the relationship or Wahlverwandtschaft between religious values of Protestantism and the economic organisation of a society (capitalism) (see Coleman, 1986, pp. 13211323; 1990, pp. 6-10).

3. Massey et al. (2009, pp. 46-48) mention the expansion of migrant networks, the distribution of income, the distribution of land, the organisation of agriculture, cultural factors, the regional distribution of human capital, the social meaning of work and the economic structure of production.

\section{Bibliography}

Bakewell, O., De Haas, H. and Kubal, A. (2013) 'Migration Systems, Pioneer Migrants and the Role of Agency', Journal of Critical Realism, 11(4), pp. 413-437.

Böcker, A. (1994) 'Chain Migration over Legally Closed Borders: Settled Immigrants as Bridgeheads and Gatekeepers', The Netherlands Journal of Social Sciences, 30(2), pp. 87-106.

Bógus, L. (2007) 'Esperança Além-Mar: Portugal no "arquipélago migratório" brasileiro', in Malheiros, J. (ed.) Imigração brasileira em Portugal. Lisboa: Alto Comissariado para a Imigração e Diálogo Intercultural, pp. 39-58.

Coleman, J.S. (1986) 'Social Theory, Social Research, and a Theory of Action', American Journal of Sociology, 91(6), pp. 1309-1335.

Coleman, J.S. (1990) Foundations of Social Theory. Cambridge, MA: Harvard University Press.

De Haas, H. (2005) 'Morocco's Migration Transition: Trends, Determinants and Future Scenarios', Global Migration Perspectives Research Papers, No. 28. Global Commission on International Migration, Geneva.

De Haas, H. (2007) 'Morocco's Migration Experience: A Transitional Perspective', International Migration, 54(4), pp. 39-70.

De Haas, H. (2010) 'The Internal Dynamics of Migration Processes: A Theoretical Inquiry', Journal of Ethnic and Migration Studies, 36(10), pp. 1587-1617.

Elster, J. (1989) Nuts and Bolts for the Social Sciences. Cambridge, UK: Cambridge University Press.

Engbersen, G. and Broeders, D. (2009) 'The State Versus the Alien. Immigration Controls and Strategies of Irregular Immigrants', West European Politics, 32(5), pp. 867-885.

Engbersen, G., Snel, E. and Van Meeteren, M. (2013) 'Declining Migration from Morocco to the Netherlands and the Diminutive Causation of Migration', IMI Oxford Working Paper Series, No. 73, International Migration Institute, University of Oxford.

Faist, T. (2015) 'Social Mechanisms in Local Transformations: Towards a Conclusion', Population, Space and Place. Advanced online publication (30 March 2015). DOI: 10.1002/psp.1927.

Faist, T., Bilecen, B., Barglowski, K. and Jadwiga Sienkiewicz, J. (2015) 'Transnational Social Protection: Migrants' Strategies and Patterns of Inequalities', Population, Space and Place. Advanced online publication (8 November 2014). DOI: 10.1002/psp.1903. 
Fonseca, M.L. and McGarrigle, J. (2014) 'Immigration and Policy: New Challenges after the Economic Crisis in Portugal', in Levine, E. and Verea, M. (eds.) Impacts of the Recent Economic Crisis (2008-2009) on International Migration. Mexico City: Universidad Nacional Autonoma de Mexico, Centro de Investigaciones sobre America del Norte, pp. 51-75.

Fussell, E. and Massey, D.S. (2004) 'The Limits to Cumulative Causation: International Migration from Mexican Urban Areas', Demography, 41(1), pp. 151-171.

Hedström, P. and Swedberg, R. (1998) 'Social Mechanisms: An Introductory Essay', in Hedström, P. and Swedberg, R. (eds.) Social Mechanisms. An Analytical Approach to Social Theory. Cambridge: Cambridge University Press, pp. 1-31.

Hedström, P. and Ylikoski, P. (2010) 'Causal Mechanism in the Social Sciences', Annual Review of Sociology, 36, pp. 49-67.

Heering, L., Van der Erf, R. and Van Wissen, L. (2004) 'The Role of Family Networks and Migration Culture in the Continuation of Moroccan Emigration: A Gender Perspective', Journal of Ethnic \& Migration Studies, 30(2), pp. 323-338.

Lucassen, L. and Lucassen, J. (2011). Winnaars en verliezers. Een nuchtere balans van vijfhonderd jaar immigratie. Amsterdam: Uitgeverij Bert Bakker.

Mahler, S.J. (1995) American Dreaming: Immigrant Life on the Margins. Princeton: Princeton University Press.

Malheiros, J. (2007). 'Os brasileiros em Portugal - a síntese do que sabemos', in Malheiros, J. (ed.) Imigração brasileira em Portugal. Lisboa: Alto Comissariado para a Imigração e Diálogo Intercultural, pp. 11-37.

Massey, D.S. (1990) 'Social Structure, Household Strategies, and the Cumulative Causation of Migration', Population Index, 56(1), pp. 3-26.

Massey, D.S., Arango, J., Hugo, G., Kouaouci, A., Pellegrino A. and Edward Taylor, J. [2009] (1998) Worlds in Motion: International Migration at the End of the Millennium. New York: Oxford University Press.

Myrdal, G. (1957) Rich Lands and Poor. New York: Harper and Row.

Myrdal, G. (1970) The Challenge of World Poverty. New York: Pantheon.

Padilla, B. (2006) 'Brazilian Migration to Portugal: Social Networks and Ethnic Solidarity', CIES E- working paper, no. 12/2006. Centro de Investigação e Estudos de Sociologia, Instituto Universitário de Lisboa.

Paul, A.M. (2011) 'Stepwise International Migration: A Multistage Migration Pattern for the Aspiring Migrant', American Journal of Sociology, 116(6), pp. 18421886.

Paul, A.M. (2013) 'Good Help Is Hard to Find: The Differentiated Mobilisation of Migrant Social Capital among Filipino Domestic Workers', Journal of Ethnic and Migration Studies, 39(5), pp. 719-739.

Peixoto, J. and Figueiredo, A. (2007) 'Imigrantes brasileiros e mercado de trabalho em Portugal', in Malheiros, J. (ed.) Imigração brasileira em Portugal. Lisboa: Alto Comissariado para a Imigração e Diálogo Intercultural, pp. 87-111.

Portes, A. (1995) The Economic Sociology of Immigration: Essays on Networks, Ethnicity and Entrepreneurship. New York: Russel Sage Foundation.

Portes, A. and Rumbaut, R.G. (1990) Immigrant America: A Portrait. Berkeley: University of California Press.

Rigney, D. (2010) The Matthew Effect. How Advantage Begets Further Advantage. New York: Columbia University Press. 
Roggeveen, S. and Van Meeteren, M. (2013) 'Beyond Community. An Analysis of Social Capital and the Social Networks of Brazilian Immigrants in Amsterdam', Current Sociology, 61(7), pp. 1078-1096.

Tilly, C. (2005) Identities, Boundaries, and Social Ties. Boulder, CO: Paradigm Publishers.

Tilly, C. (2010) 'Mechanisms of the Middle Range', in Calhoun, C. (ed.) Robert K. Merton. Sociology of Science and Sociology of Science. New York: Columbia University Press, pp. 54-62. 